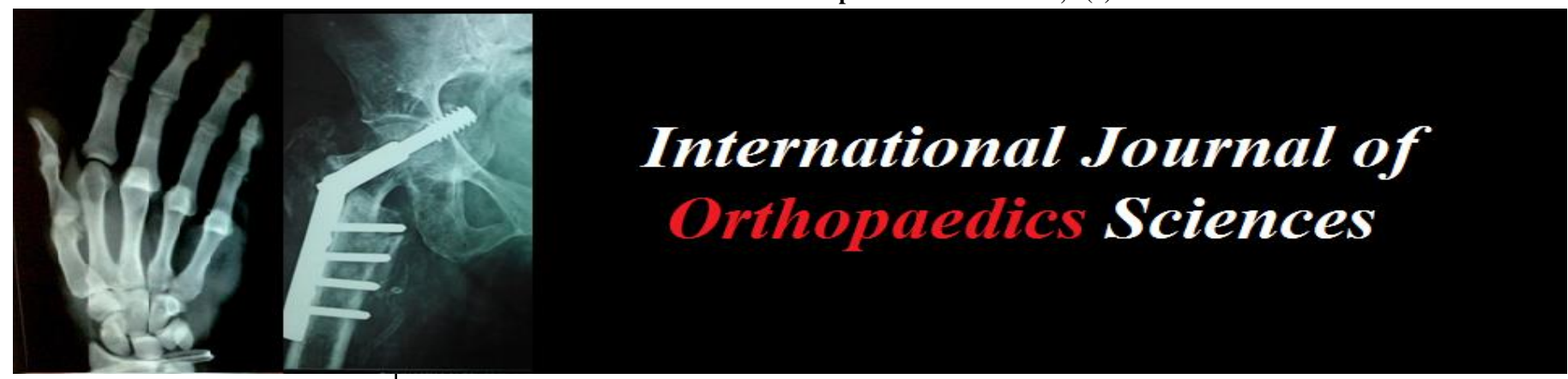

ISSN: $2395-1958$

IJOS 2018; 4(4): 617-620

(C) 2018 IJOS

www.orthopaper.com

Received: 22-08-2018

Accepted: 23-09-2018

Bharghava Ram Uppalapati Department of Orthopaedics, Sri Ramachandra Medical

University, Chennai,

Tamil Nadu, India

Gokul Raj Dhanarajan

Department of Orthopaedics, Sri Ramachandra Medical

University, Chennai,

Tamil Nadu, India

Thiyagarajan U

Department of Orthopaedics,

Sri Ramachandra Medical

University, Chennai,

Tamil Nadu, India

Senthil L

Department of Orthopaedics,

Sri Ramachandra Medical

University, Chennai,

Tamil Nadu, India

Pradeep J

Department of Orthopaedics, Sri Ramachandra Medical

University, Chennai,

Tamil Nadu, India

Correspondence

Bharghava Ram Uppalapati

Department of Orthopaedics,

Sri Ramachandra Medical

University, Chennai,

Tamil Nadu, India

\section{A novel technique of plate positioning for fixation of posterior column acetabular fractures by modified Kocher-Langenbeck technique: A case series}

\author{
Bharghava Ram Uppalapati, Gokul Raj Dhanarajan, Thiyagarajan U, \\ Senthil L and Pradeep J
}

DOI: https://doi.org/10.22271/ortho.2018.v4.i4h.72

\begin{abstract}
Introduction: Modified kocher-langenbeck technique aims at achieving osteosynthesis by creating two windows: between the gluteus medius and piriformis superiorly and between external rotators and ischial tuberosity inferiorly. The reconstruction plate can be slid under the piriformis and the short external rotators, we propose an easy way for the placement of the reconstruction plate Case report: We present a series of three cases with acetabular fractures posterior column fixed with reconstruction plates by modified kocher-langenbeck approach with a minimum follow up of 2 years.

Case 1: $37 \mathrm{yr}$ male patient with right posterior column fracture left anterior and posterior column fracture, right posterior column and left anterior column are fixed with percutaneous screws, left posterior column fracture fixed with reconstruction plate and screws.

Case 2: 45yr male patient with left posterior column fracture fixed with reconstruction plate and screws. Case 3: $41 \mathrm{yr}$ male patient with right posterior column fracture anterior column fracture fixed with reconstruction plate and screws. All the patients posterior column was fixed using modified kocherlangenbeck approach, all patients were followed for a period of 2 years, all patients had excellent outcome, there is no incidence of avascular necrosis of head in any case. Discussion: Modified kocherlangenbeck approach is tissue preserving and prevents damage to the vascularity of the head, in all the cases after reduction of fracture, an umbilical tape was tied to the end of the reconstruction plate using a long artery forceps the umbilical tape is pulled under the submuscular tunnel thus positioning the reconstruction plate under the intact short external rotators, the plate is fixed with appropriate screws. Use of this technique provides an easy positioning of reconstruction plate.
\end{abstract}

Keywords: Acetabular fractures, posterior column, reconstruction plate, kocherlangenbeck

\section{Introduction}

Displaced fractures of the acetabulum are best treated with anatomical reduction and rigid internal fixation. Superior outcomes are associated with anatomic reduction of the weight bearing dome of the acetabulum. Most of the acetabular fractures $(98 \%)$ can be managed by a single appropriate operative approach. Modified kocher-langenbeck technique aims at achieving osteosynthesis by creating two windows: between the gluteus medius and piriformis superiorly and between external rotators and ischial tuberosity inferiorly. The approach spares the division of external rotators and of the abductors of the hip, thus preventing iatrogenic damage to the vascularity of the head of the femur and of the fracture fragments. The reconstruction plate can be slid under the piriformis and the short external rotators, we propose an easy way for the placement of the reconstruction plate

Materials and methods

Case report: We present a series of three cases with acetabular fractures posterior column fixed with reconstruction plates by modified kocher-langenbeck approach with a minimum follow up of 2years.

Case 1: $37 \mathrm{yr}$ male patient sustained road traffic accident 4 wheeler vs 4 wheeler diagnosed to have with right posterior column fracture left anterior and posterior column fracture, right 
posterior column and left anterior column are fixed with percutaneous screws, left posterior column fracture fixed with reconstruction plate and screws. (Figure 1,2,3). 2 year follow up patient resumed activities with no complications.

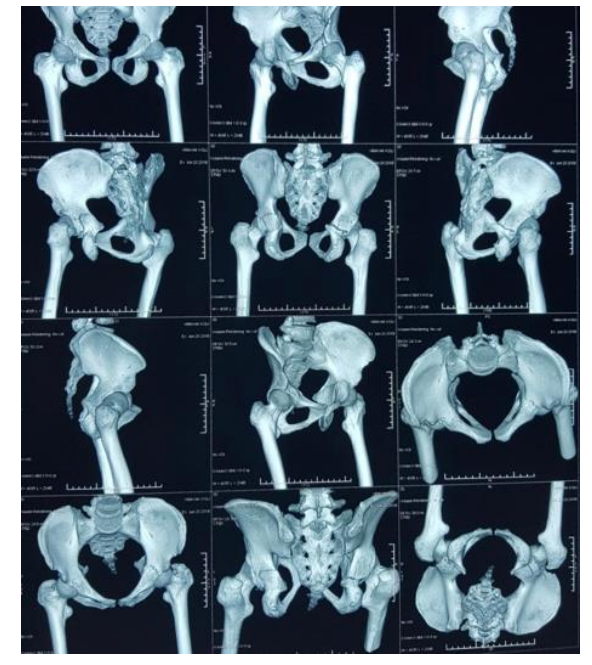

Fig 1: Preoperative CT scan
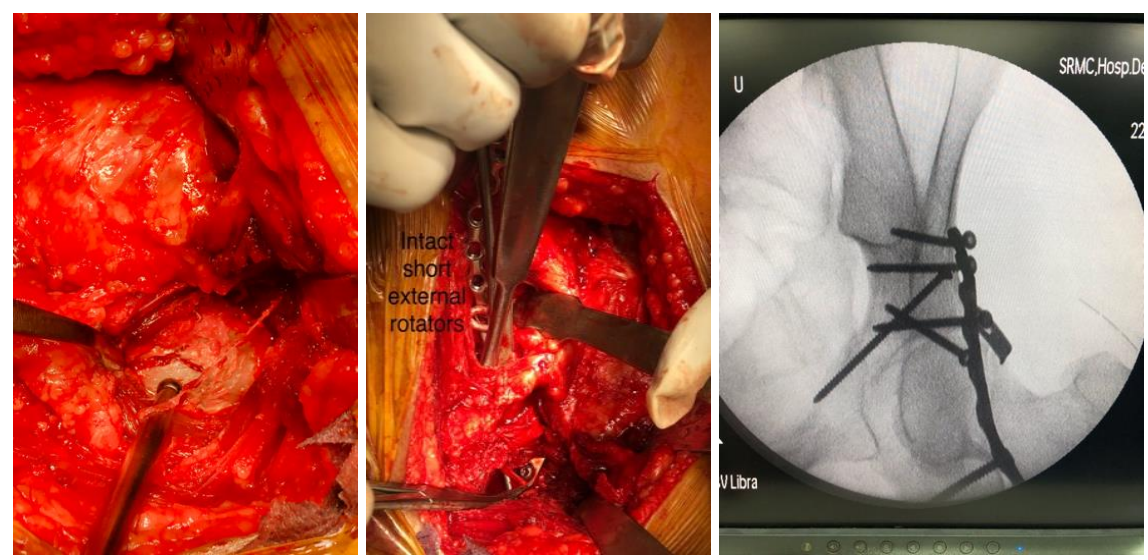

Fig 2: intra operative fracture reduction and sliding of plate under the intact short external rotators.
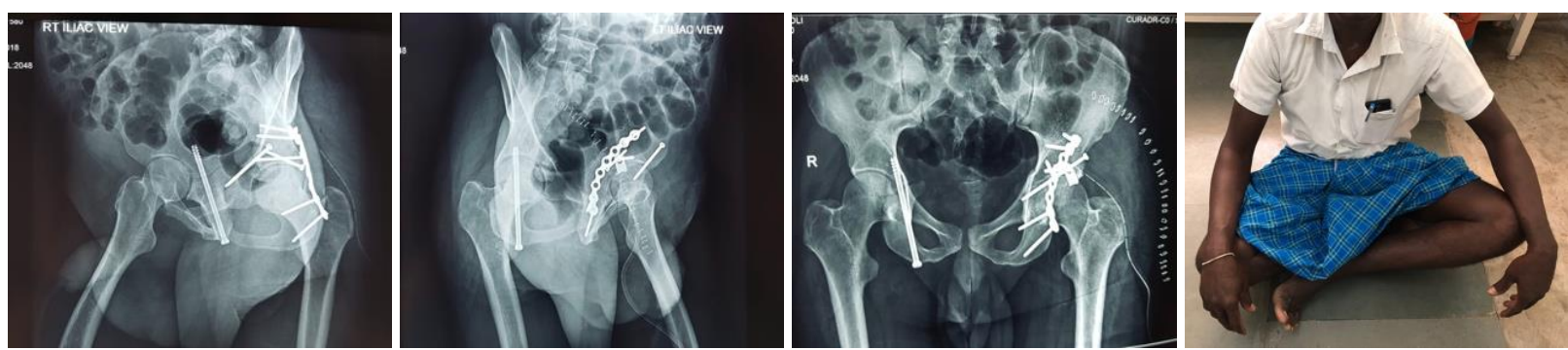

Fig 3: Post operative xray and clinical picture at follow up

Case2: 45yr male patient sustained injury by fall from height. Diagnosed with left posterior column fracture fixed with reconstruction plate and screws. Patients had good results with no complications. (Fig 4, 5, 6)

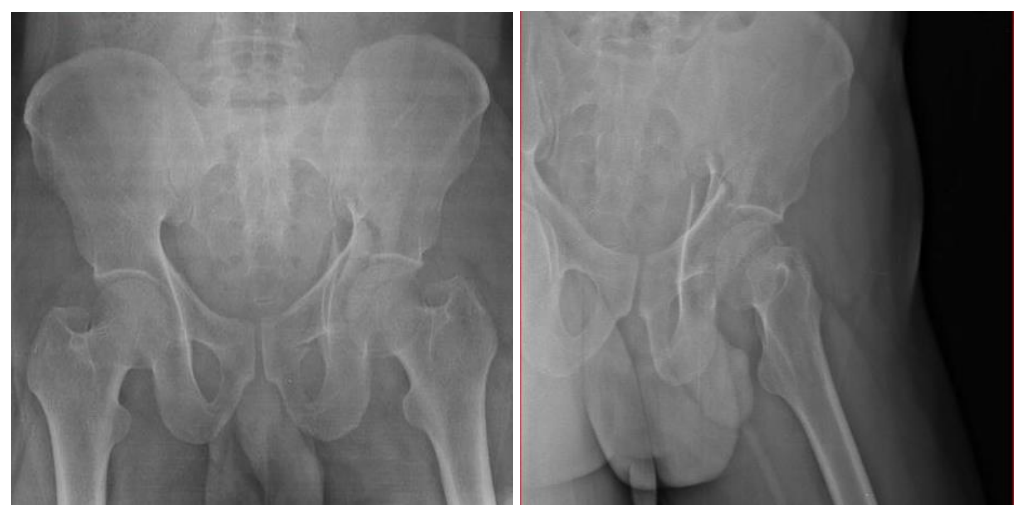

Fig 4: PreOp xrays

$\sim 618 \sim$ 

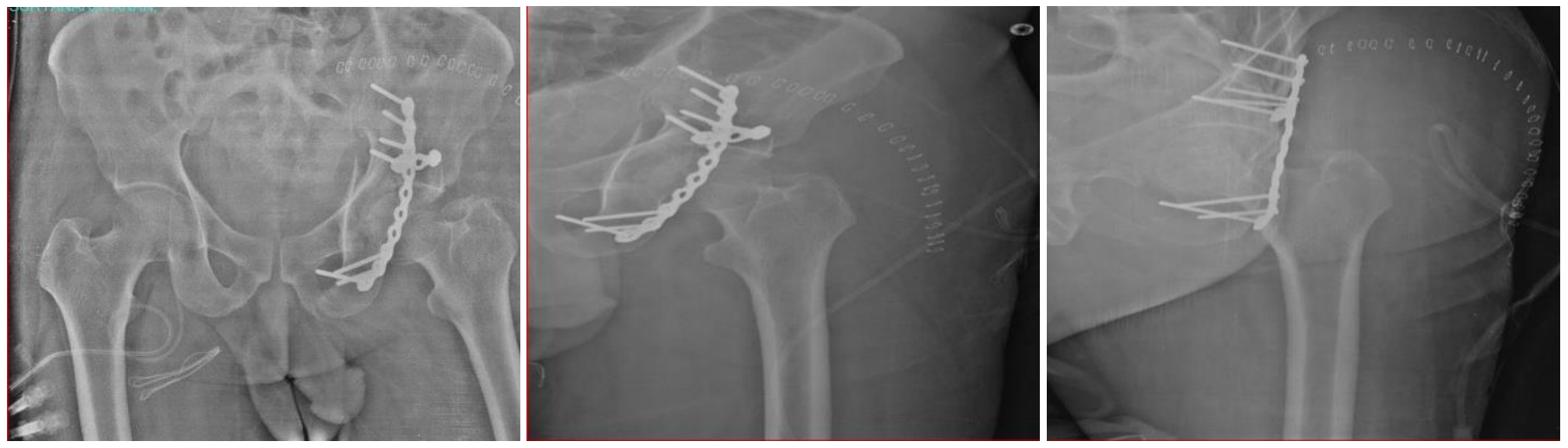

Fig 5: immediate post op xray

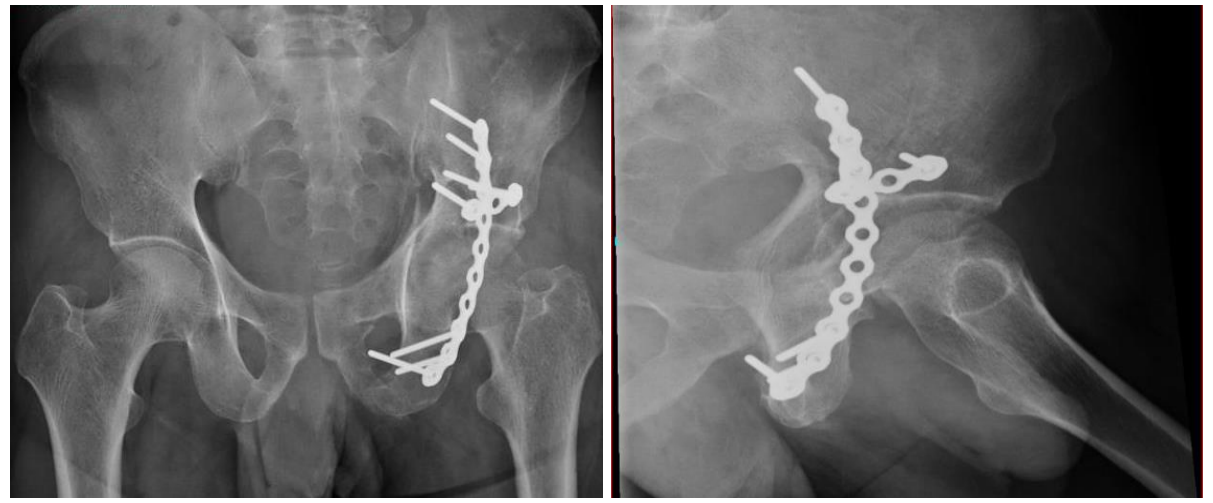

Fig 6: 2 years post op xray

Case 3: 41yr male patient with right posterior column fracture anterior column fracture firxed with reconstruction plate and screws. Had good results (fig 7, 8, 9).
All the patients posterior column was fixed using modified kocher-langenbeck approach, all patients were followed for a period of 2 years, all patients had excellent outcome, there is no incidence of avascular necrosis of head in any case.

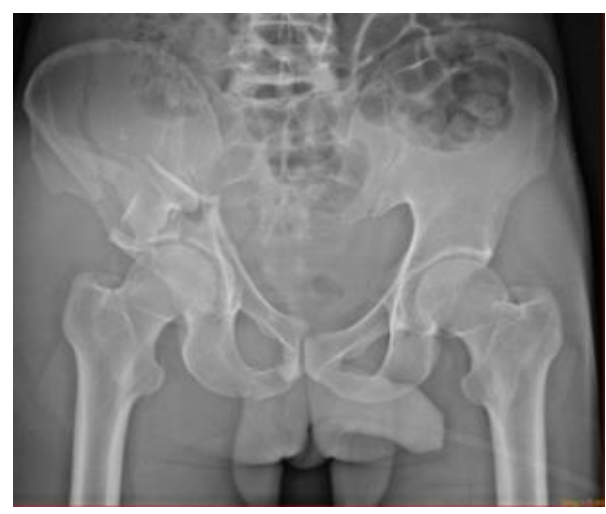

Fig 7: pre op xray
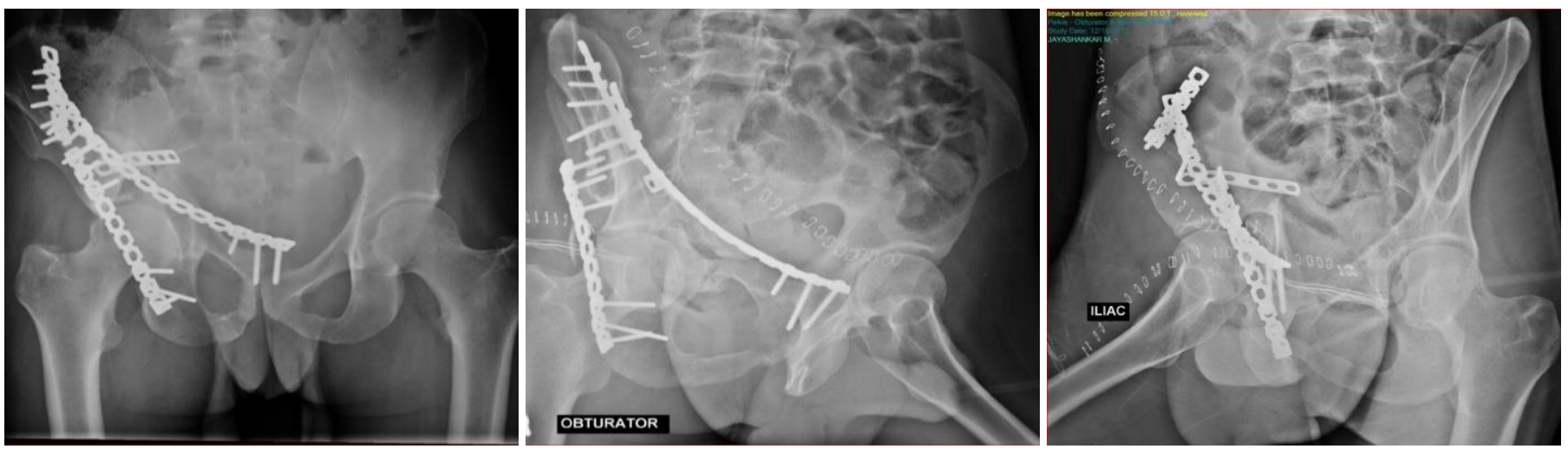

Fig 8: immediate postop xray 


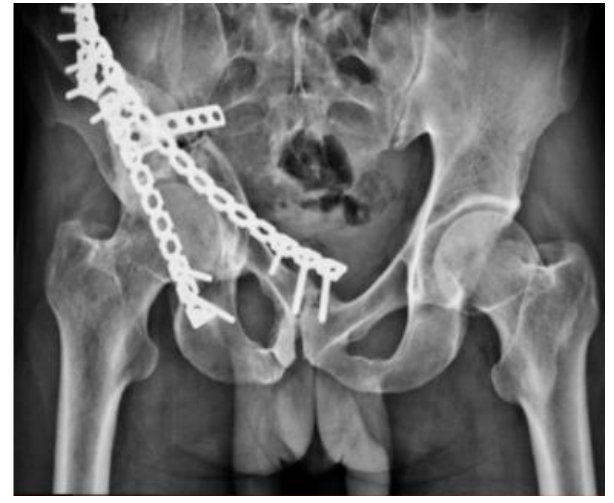

Fig 9: 2 year followup xray

\section{Discussion}

Modified kocher-langenbeck approach is tissue preserving and prevents damage to the vascularity of the head, in all the cases after reduction of fracture, reconstruction plate was prebent according to the anatomy, a submuscular tunnel was made using a cobbs elevator persevering the short external rotators. An umbilical tape was tied to the end of the reconstruction plate using a long artery forceps the umbilical tape is pulled under the submuscular tunnel thus positioning the reconstruction plate under the intact short external rotators, the plate is fixed with appropriate screws. Use of this technique provides an easy positioning of reconstruction plate

\section{Conclusion}

We believe that modified kocher-langenbeck approach makes the procedure less invasive, shortens the operative time, minimises blood loss.

\section{References}

1. Matta JM. Fractures of the acetabulum: Accuracy of reduction and clinical results in patients managed operatively within three weeks after the injury. J Bone Joint Surg Am. 1996; 78:1632-45.

2. Moed BR, Carr SE, Watson JT. Open reduction and internal fixation of posterior wall fractures of the acetabulum. Clin Orthop Relat Res. 2000; 377:57-67.

3. Moed BR, Willson Carr SE, Watson JT. Results of operative treatment of fractures of the posterior wall of the acetabulum. J Bone Joint Surg Am. 2002; 84-A:7528.

4. Routt ML Jr, Swiontkowski MF. Operative treatment of complex acetabular fractures. Combined anterior and posterior exposures during the same procedure. J Bone Joint Surg Am. 1990; 72:897-904.

5. Harris AM, Althausen P, Kellam JF, Bosse MJ. Simultaneous anterior and posterior approaches for complex acetabular fractures. J Orthop Trauma. 2008; 22:494-7.

6. Griffin DB, Beaulé PE, Matta JM. Safety and efficacy of the extended iliofemoral approach in the treatment of complex fractures of the acetabulum. J Bone Joint Surg Br. 2005; 87:1391-6.

7. Reinert CM, Bosse MJ, Poka A, Schacherer T, Brumback RJ, Burgess AR. A modified extensile exposure for the treatment of complex or malunited acetabular fractures. J Bone Joint Surg. Am. 1988; 70:329-37.

8. Mears DC, Rubash HE. Extensile exposures of the pelvis. Contemp Orthop. 1983; 6:21-32.

9. Moroni A, Caja VL, Sabato C, Zinghi G. Surgical treatment of both-column fractures by staged combined ilioinguinal and Kocher-Langenbeck approaches. Injury. 1995; 26:219-24.

10. Magu NK, Rohilla R, Arora S, More H. Modified Kocher-Langenbeck approach for the stabilization of posterior wall fractures of the acetabulum. J Orthop Trauma. 2011; 25:243-9.

11. Letournel E, Judet R. In: Elson RA, editor. Fractures of the Acetabulum, New York: Springer, 1993.

12. Ficat $P$, Arlet J. Necrosis of the femoral head. In: Hungerford DS, editor. Ischemia and Necrosis of Bone. Baltimore: Williams and Wilkins. 1980; pp. 53-74.

13. Brooker AF, Bowerman JW, Robinson RA, Riley LH Jr. Ectopic ossification following total hip replacement. Incidence and a method of classification. $\mathrm{J}$ Bone Joint Surg Am. 1973; 55:1629-32.

14. Giannoudis PV, Grotz MR, Papakostidis C, Dinopoulos H. Operative treatment of displaced fractures of the acetabulum. 